\title{
The Establishment of the Internal Control Frame System of Colleges
}

\author{
Weixing Wang \\ Jiangsu Polytechnic University, Changzhou 213164, China \\ E-mail: wangwx5758@sina.com
}

\begin{abstract}
The key to establish the internal control frame system of colleges is to confirm the internal control target and the control factors. The internal control target concludes the schooling effect and efficiency, the safety and integrity of assets, the real, complete, and useful accounting and management information, and following national laws and regulations. The factors of internal control could be divided into two layers. The first layer is composed by the control environment, the control system, and the supervision and evaluation, and the control environment is the base, the control system is the core and the supervision and evaluation are the guarantee.
\end{abstract}

Keywords: Colleges, Internal control, Control target, Control factors

With the development of the market economy, the competition is more and more drastic, and because of the pressure of survival, the management level of enterprises should be enhanced continually, and the theory and practice of internal control are more and more popular. In China, the China Ministry of Finance constituted and issued the "Basic Standard for Enterprise Internal Control" in 2009 with the China Securities Regulatory Commission, the Auditing Administration of China, the China Banking Regulatory Commission, and the China Insurance Regulatory Commission. Relative to enterprises, the internal control of colleges is still weak, and relative researches have not been noticed by the theory academy, and the practice activities have not been developed profoundly. Therefore, whether for the theoretical meaning or for the practical meaning, it is very necessary to deeply research the internal control of colleges and establish the internal control frame system of colleges.

\section{Important function to establish the internal control frame system of colleges}

In recent years, the higher education of China develops very quickly, and relative data show that comparing with the year of 1978, the scale of college students increased to 17.388 million in 2006 from 0.856 million, a growth proportion of $1931.3 \%$, and the average yearly increase was $11.35 \%$, and the average college student amount was 9313, and the average yearly growth in these eight years was $13.4 \%$ (source from China Statistical Yearbook). The quickly development of higher education brings not only opportunities, but also challenges, and the competitive situation among colleges have been gradually formed. The practice indicates that when the organization is bigger and bigger and the employees are more and more, to instruct and limit workers' random is more and more important, and the effective management should be turned to instruct and control workers. It is obvious that it has been the important task at present to deeply research the internal control theory of colleges, explore scientific internal control system, strengthen the control of various economic activities, and promote the scientific, healthy, and durative development of Chinese colleges.

To establish the internal control activities of colleges on scientific and effective principals, and exert their corresponding control and harmonizing function, the systematic internal control theory and the internal control theory frame system should be established according to the property and the running character of colleges. The key to establish the internal control frame system of colleges is to confirm the internal control target and the control factors.

\section{Confirming the internal control target of colleges}

To establish the internal control frame system of colleges, the internal control target of college should be confirmed first.

The report of COSO defined the internal control target as the efficiency and effect of operation, the reliability of financial report, and the compliance of relative laws and regulations. The "Basic Regulations of Internal Accounting Control Regulations" of China reduced the target of enterprise internal control to five aspects, i.e. the enterprise strategy, the efficiency and effect of operation, the reliability and integrity of financial report and management information, the safety and integrity of assets, the compliance of national laws and regulations, and relative supervision requirements.

As an economic organization, college has many common requirements in the internal control with enterprises, 
but college is non-profitable organization, and its schooling target is significantly different with the target of enterprises, and their operation properties and contents are also largely different, so the internal control target of colleges should not simply copy the report of COSO or the contents in the internal accounting control regulations of enterprises.

According to the characteristics and running actuality of colleges, the internal control target of colleges could be confirmed from following aspects.

\subsection{Safety, integrity and efficient utilization of assets}

According the higher education law, colleges legally manage and use the properties from investors running colleges, national finance imbursements, and endowers, and these properties used in teaching and research should not be used in other items. To ensure the normal running of the teaching, research, and service of colleges, effective prevention measures need to be adopted to avoid fraudulent practices, put right in time and ensure the safety and integrity of assets and capitals. The main target of early internal control was to prevent disadvantages and put right and ensure the safety and integrity of assets, and up to now, the internal control of western developed countries such as US have changed largely, and the distortion of financial information and the compliance of efficiency and laws have been the main control problems before them. The internal control research of China started lately, and the internal control of non-profitable organizations such as colleges is in the initial state, so the safety and integrity of assets should be one of main targets of internal control.

\subsection{Real, complete, and useful accounting information}

The core content of early internal control includes the check among account books, the coherence of account book record and assets, and the reliability of accounting data. With the increasing diversification of the internal control target, the accounting control is not only limited to ensure the reality and reliability of accounting information. On the one hand, the current accounting management system of colleges could better guarantee the reality and integrity of accounting materials. On the other hand, colleges are non-profitable units, and their basic income and expenses check deal with a little taxation, and the current check system doesn't involve cost, charges and profits, and most colleges are founded by the government, and only a few private colleges are founded by individuals or juridical persons, and the accounting reports of these private colleges are mainly sent to the superior charge department or units, which doesn't like those enterprises. For various direct benefits such as taxation and stock price, the distortion of accounting information will often happen. Therefore, the emphasis of college internal control is not the reality and reliability of accounting information, but the full utilization of existing accounting information system and materials.

\subsection{Schooling effect and efficiency}

Though colleges are non-profitable organizations, and they don't take the maximization of profit as their target, but to better realize the schooling target, they also need to pursue the efficiency and benefit. By the internal control, colleges could optimize the resource allocation, push the resource sharing among colleges, enhance the using efficiency of assets, especially the fixed assets such as experiment equipments, and exert the functions of limited schooling capitals and various teaching and research resources to the largest extent, make the college to complete the task of cultivating talents, scientific research, and serving the society with high quality, and satisfy the demands of the country and the society. To enhance the economic benefit of schooling for colleges could better realize their social benefits.

\subsection{Following national laws and regulations}

Running the college legally and governing the college legally is the essential base of colleges, and the colleges are the place centralizing intellectuals and young students, and they have active ideas and strong legal consciousness, and colleges should better follow relative laws and regulations. In the legal society, following relative laws and regulations is the necessary condition for the survival of enterprises even any one unit, so the compliance of relative laws should be one of necessary internal control target of colleges.

These internal control targets are associated each other, and form the internal control target system of colleges.

\section{Study on the factors of the college internal control theory frame}

The COSO report divided the factors of internal control into five parts, i.e. the control environment, the risk evaluation, the control activity, the information communication, and the supervision. The basic principal of Chinese internal control used the COSO report as reference, and includes the control environment, the risk evaluation, the control measures, the information and communication, and the supervision and check.

According to the management characteristics of colleges, the internal control factors should be divided into two 
layers.

\subsection{Factors of the first layer of college internal control}

According to the control theory, the control process generally includes three basic stages, i.e. confirming the control target, implementing and measuring the effect, and correcting the implementation deviation, and one effective control should be the closed control process with the feedback loop. The internal control is a dynamically repetitive process to discover problems, solve problems, discover new problems, and solve new problems. Starting form the basic theory of the control theory, the first layer of the college internal control factor should be composed by the control environment, the control activity, and the supervision and evaluation.

As a special control system, college can not exist independently, and it is in certain environment. The control environment includes various factors influencing the establishment, strengthening or weakening of special policies, procedures, and efficiencies. The control environment is the engine to push the control work, and it is the base of all other internal control components, the environment that all control modes and methods survive and run. The control environment includes the internal environment and the external environment, and the former could be controlled and adjusted by the college, and the latter is not. Therefore, the control environment mainly means the internal control environment of colleges.

The control activity means the whole process to establish a series of polices and procedures to standardize various operations and managements of colleges for the realization of the organizational target, and it is one of the most important facts in the college internal control, and the core of the whole internal control theory frame.

The supervision and evaluation is to check, supervise, and evaluate the running effect and quality of the internal control system, and the feedback system combining the supervision and evaluation is another important factor in the college internal control, which guarantees the effective running and the realization of the target for the system.

In above three first-layer factors, the control environment is the base, the control activity is the core, and the supervision and evaluation is the guarantee.

\subsection{Factors of the second layer of college internal control}

The first-layer factors contain abundant concrete control contents, and they should be further researched to be decomposed and form the second-layer internal control factors.

\subsubsection{The second layer factor analysis of control environment}

In the evolvement process of the internal control theory, the internal control environment is thought as the necessary part in various stages of the internal control. The internal control structure stage divides the control environment into seven aspects, i.e. the management philosophy and management mode, the organization structure, the auditing committee, the personnel policy and procedure, the method of authorization and distribution responsibility, the internal auditing department, and the external influence. The internal control frame stage also divides the control environment into seven aspects, i.e. the management philosophy and management style, the organization structure, the directorate and its auditing committee, the human resource policy and affair, the responsibility and right allocation mode, the honesty quality and value view, and the competence ability. Yang Yonghong thought that the control environment included the directorate of enterprise, the management personnel's morality, personal integrity, value view, quality, and ability, the managers' management philosophy and management concept, the enterprise culture, the regulations and systems of enterprise, the information and communication system.

According to the research result of enterprise internal control, the internal control environment of college should conclude following two aspects combining with the actuality of higher education.

The first aspect includes the organization structure and the organization culture. The organization structure is the carrier to implement the internal control activity, and the organization culture influences the consciousness and concept of internal control. The juridical person governance structure is the most important content of control environment. In colleges, the organization culture means the college culture, i.e. a special social culture formation based on long-term schooling practice, historical accumulation, and influences of internal and external environment. The college culture mainly includes the spirit culture, the system culture, and the environment culture, and the system culture is the important guarantee to develop and push the internal control.

The second aspect includes the information and communication. The information and communication system is the necessary condition to implement the internal control. The system requires the college to correctly record the internal operation activities of colleges, adopt proper method to distinguish and abstract information, and collect 
and classify external relative information to communicate, and make mangers and teaching staff to carry out their responsibilities. Good information and communication could help to enhance the efficiency and effect of internal control. Furthermore, the information from the internal control activity is also the bridge to connect the control activity with the supervision factor.

\subsubsection{The second layer factor analysis of control activities}

The control activity is the most important component in the internal control of colleges, and it contains much more contents.

First, the comprehensive budge management is very important for colleges. The main capital source of public colleges of China is financial allotments and schooling incomes, and the amount of financial allotment of one college is mainly confirmed according to the department budget, and the payout control of college is mainly implemented by making and performing the budget. In other words, the income and expenses of colleges are mainly controlled by the budget. Therefore, one important factor of internal control of college is to make and perform the budge.

Second, it is very important to adopt what control procedure and control method for the whole control activity. In the control activity of unit, to use scientific control procedure and method is very important to realize the control target. Therefore, scientific and effective control activity is an important problem which should be solved in the internal control factors.

Third, it contains the identification and control of risk. The risk identification means the processes to judge, classify, and identify the risks and potential risks of colleges. The risk control is to adopt many measures such as retaking, limiting, transferring, dispersing, and solving to control the schooling risk and financial risk in the tolerance range. The financial report-oriented internal control starts from the minimum risk. At present, the higher education is in the quick development term, and the expansion of the schooling scale and the introduction of the credit capital will certainly bring the schooling risk and financial risk, and colleges should not fear the risk to hesitate to mover forward, but confirm certain risk tolerant range, and control the risk in the acceptable range.

\subsubsection{The factor analysis of supervision and evaluation}

The supervision and evaluation is only one factor, but it contains two aspects. The supervision is to transfer the information to the control body by paying attention to the result of certain time, to correct the deviation of the target. By the periodical supervision, the deficiencies in various economic operations, internal institutions, and posts existing in the internal control could be improved, and the internal control will be more perfected and effective. The evaluation is to supervise and control the internal controls of various functional departments, and by the evaluation, the basic situation of internal control could be described, and the weak parts in the internal control could be advised and improved.

The supervision is a usually durative activity, and the evaluation is periodic, and usual supervision could provide important information of the periodic evaluation, and the result of periodic evaluation could also open out the problems existing in the supervision, so both of them are compensated and improved each other. Therefore, only the control activity with supervision and evaluation is the effective and matured control activity.

Above control targets and factors compose the internal control theory frame system of colleges (seen in Figure 1).

\section{References}

COSO. (1992). Internal Control-integrated Framework.

Liu, Jing \& Li, Zhumei. (2005). Some Thinking on Internal Control Environment. Accounting Research. No.2. P.73-75.

Liu, Jinwen. (2004). "Three Factors": the Optimal Combination of the Internal Control Theory Framework. Auditing Research. No.2. P.83-85.

Pan, Xiuli. (2001). Research on Issues of Internal Accounting Control. Accounting Research. No.6. P.22-25.

Yan, Dawu \& Yang, Youhong. (2001). Tentative on the Construction of Internal Control Framework. Accounting Research. No.2. P.9-14.

Zhang, Junmin. (2001). The Structure of Objectives of Firm's Internal Accounting Control and Its Stratification Design. Accounting Research. No.5. P.44-47. 


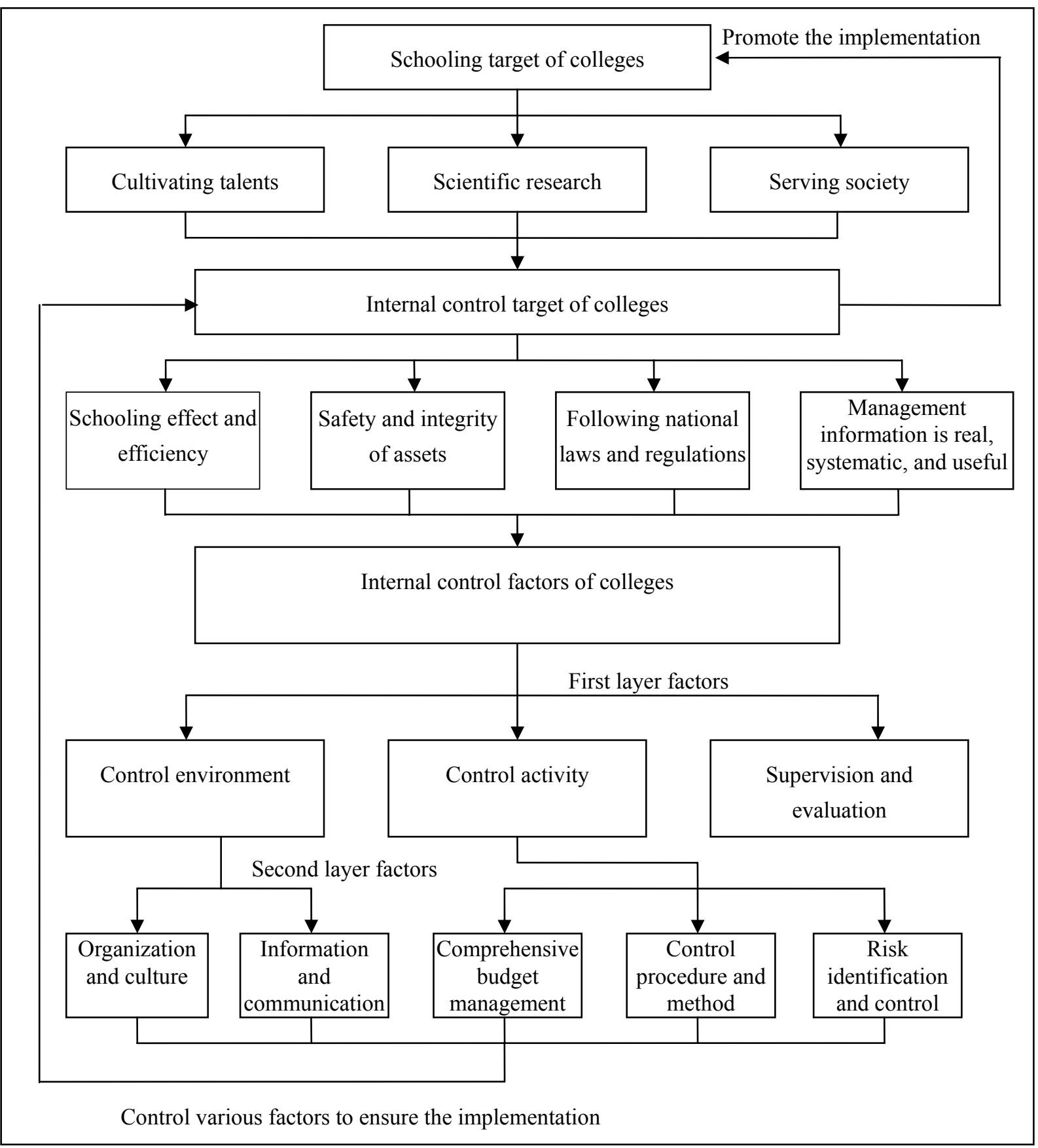

Figure 1. Internal Control Framework System of Colleges 